\title{
O Papel da Gramática em Livros Didáticos de Língua Portuguesa: um olhar sobre o ensino da oração subordinada adjetiva
}

\author{
The Role of the Grammar on Portuguese Textbooks: \\ A LOOK ON TEACHING OF RELATIVE CLAUSE
}

\section{Aliana Lopes CÂMARA * Lília Santos ABREU-TARDELLI **}

Resumo: Estuda-se, neste artigo, o modo como os livros didáticos de Língua Portuguesa do Ensino Fundamental II, aprovados pelo Programa Nacional do Livro Didático-2014, abordam o ensino de gramática. Para isso, partimos inicialmente da comparação entre a proposta dos manuais quanto ao ensino da gramática e o que se efetivou no livro do aluno, mais especificamente em relação ao tratamento dado ao ensino da oração adjetiva. Propomos, a partir de estudos sobre a descrição funcional da oração adjetiva, verificar como alguns aspectos descritivos podem ser usados no ensino da oração adjetiva, visando o desenvolvimento das habilidades de leitura e escrita. Para tanto, toma-se como arcabouço teórico as diferentes concepções de gramática propostas em Travaglia $(2009,2011)$ e a Gramática Discursivo-Funcional (HENGEVELD; MACKENZIE, 2008). O estudo aponta a importância de se enfatizar, no ensino, o papel coesivo estabelecido pelo pronome relativo prefaciador da oração subordinada adjetiva, de se entender a adjetiva explicativa a partir de sua função argumentativa e de se rever a distinção entre os subtipos de orações adjetivas a partir do critério de omissão da oração subordinada. Palavras-chave: Ensino de gramática. Análise de livro didático. Funcionalismo.

\footnotetext{
* Doutoranda na Universidade Estadual Paulista Julio de Mesquita Filho, São José do Rio Preto. Professora da EE Justino Jerry Faria. Contato: aliana.precioso@gmail.com. ** Doutorado em Linguística Aplicada e Estudos da Linguagem (2006) na Pontifícia Universidade Católica de São Paulo. Professor Assistente Doutor da UNESP. Contato: lilia@ibilce.unesp.br.
} 
Abstract: This paper studies how the textbooks of Portuguese Language of Secondary School, approved by the Programa Nacional do Livro Didático-2014, approach the teaching of grammar, in particular as regards the treatment of the relative subordinate clause. For this, first we start with the comparison between the proposals manuals for teaching grammar and what was accomplished in the student book. Furthermore, we propose here an interface between the results of the analysis of textbooks and functional description of the relative clause. In other words, we try to verify as some descriptive aspects can be used in the teaching of relative clause, with the aim of developing reading and writing skills. In order to do that, we take as theoretical framework the different conceptions of grammar proposed in Travaglia (2009, 2011) and Functional Discourse Grammar (HENGEVELD; MACKENZIE, 2008). This research points to the need to emphasize the cohesive role established by the relative pronoun that introduces the relative clause, to understand the non-restrictive relative clause from its argumentative function and to review the distinction between subtypes of adjective clause from the criteria of omission of the subordinate clause.

Keywords: Grammar teaching. Textbooks analysis. Functionalism.

\section{Palavras Iniciais}

Já há algum tempo, pesquisadores (NEVES, 1993, 2002, 2011; POSSENTI, 1996; ANTUNES, 2007; BAGNO, 2007, 2011; TRAVAGLIA, 2009, 2011; CASTILHO, 2012, dentre outros) têm-se debruçado sobre reflexões acerca do ensino de gramática na escola. Além de apontarem para certas questões problemáticas do ensino de gramática, tais como o descaso com as variedades não padrão do português e o ensino mecanicista e descontextualizado dos aspectos linguísticos, alguns deles também se preocupam em propor formas alternativas para o ensino de alguns tópicos gramaticais. Destacam-se, nesse sentido, as gramáticas pedagógicas de Bagno (2011) e Castilho (2012), que, com base em resultados descritivos e indagações sobre a língua, propuseram manuais para o ensino da gramática do português. Essas iniciativas apontam para um amplo e interessante campo de estudo: a conexão entre a descrição linguística e a prática educativa. Este artigo, que tem como objeto de estudo o ensino da oração adjetiva, é mais uma iniciativa que pretende relacionar aspectos descritivos da língua com o ensino de 
gramática. Espera-se que alguns professores consigam, a despeito de sua intensa e cansativa jornada (às vezes, dupla ou tripla) de trabalho, ter acesso não só a esta proposta, mas também a tantas outras que possam ajudá-los na difícil, mas não impossível tarefa de se ensinar gramática.

Dentre os vários caminhos apontados por essas propostas, destaca-se a importância de se refletir sobre como os resultados das pesquisas linguísticas podem auxiliar no desenvolvimento da leitura e da escrita na sala de aula, por meio da explicitação dos mecanismos linguísticos que contribuem para a construção textual. Ao debruçarmos especificamente sobre a oração adjetiva, pretendemos demonstrar aqui de que modo esse conteúdo gramatical específico pode ser ensinado tendo-se em vista os aspectos pragmáticos e textuais subjacentes ao seu funcionamento. Com isso, pretendemos mostrar como os conteúdos gramaticais de um modo geral também podem ser ensinados em uma perspectiva mais contextualizada e menos normativa. Para isso, faz-se necessário, cada vez mais, o diálogo entre a Linguística Aplicada e a Linguística que se propõe à descrição da língua.

Ademais, também se pretende propor novas formas de trabalho para esse conteúdo didático, com base na descrição discursivo-funcional da oração adjetiva, sem se fazer uma transposição direta da teoria para a prática, e sim refletindo sobre algumas questões teóricas que possam levar a um ensino mais reflexivo e produtivo. A inovação desta pesquisa, portanto, encontra-se justamente no fato de haver poucos trabalhos sobre o português que, baseados no arcabouço teórico adotado por nós, proponham uma reflexão sobre o ensino de gramática ${ }^{1}$.

A escolha da Gramática Discursivo-Funcional (doravante GDF) devese ao fato de esta ser uma teoria funcionalista, em que a gramática é vista como constituída por quatro níveis de análise, a saber, o pragmático, o semântico, o morfossintático e o fonológico, que estão hierarquicamente relacionados, indo do primeiro em direção ao último. Tal modelo gramatical, em que as intenções comunicativas do falante/escritor determinam a

${ }^{1}$ A única iniciativa nesse sentido foi realizada por alguns integrantes do Grupo de Pesquisa em Gramática Discursivo-Funcional, de São José do Rio Preto, coordenado pela Prof. ${ }^{a}$ Erotilde Goreti Pezatti, que, em 2011, apresentaram, no XVI Congreso Internacional de la Alfal (Alcalá de Henares - Espanha), trabalhos de análise de gramáticas e livros didáticos de língua portuguesa, formulando reflexões sobre o ensino da subordinação. 
formulação das expressões linguísticas, está de acordo com as atuais propostas de ensino de gramática, que defendem que a gramática deve ser estudada na interação, como um mecanismo do falante/escritor para atingir seus objetivos comunicativos.

Este artigo se encontra dividido da seguinte forma: inicialmente, discutimos alguns pressupostos teóricos norteadores do ensino de gramática na atualidade (TRAVAGLIA, 2009, 2011). Em seguida, apresentamos brevemente o arcabouço teórico da GDF (HENGEVELD; MACKENZIE, 2008), dentro do qual destacamos as características descritivas da oração subordinada adjetiva. $\mathrm{Na}$ segunda seção, apresentamos a metodologia e o corpus desta pesquisa e, na terceira seção, analisamos como a oração adjetiva é apresentada no livro didático (doravante LD) e como são elaboradas as atividades referentes ao tema, buscando-se verificar se de fato se relaciona o ensino de gramática com o de leitura e produção de textos. Por fim, na última seção, apresentamos as considerações finais, momento em que propomos uma interface entre a descrição linguística e o ensino da oração adjetiva.

\section{Fundamentação Teórica}

\subsection{Algumas considerações sobre o ensino de gramática}

Defende-se aqui, com base em Travaglia (2009, 2011), que o ensino de gramática deve visar essencialmente ao desenvolvimento da competência comunicativa do aluno, definida como a capacidade de se comunicar nas mais diversas situações de interação, mobilizando os recursos linguísticos necessários para atingir seus objetivos comunicativos. A competência comunicativa, portanto, envolve não só a competência gramatical de gerar sequências gramaticais, mas também a competência textual para reconhecer as regularidades e os princípios de organização e construção do texto. É justamente a compreensão do funcionamento dos elementos linguísticos no texto que possibilita ao aluno compreender e construir textos adequados às diversas situações de interação.

Portanto, acreditamos que faz mais sentido estudar os recursos linguísticos como mecanismos para produzir/entender determinados efeitos de sentido, visando determinadas intenções comunicativas. Essa posição é fundamental para a produção de textos, já que o aluno deve saber mobilizar 
os mecanismos necessários para atingir os efeitos de sentido desejados e deve ser capaz de traçar um percurso argumentativo adequado aos objetivos que deseja atingir.

Essa visão de gramática difere fundamentalmente da noção de gramática normativa predominante na escola. A gramática normativa é um conjunto de normas, leis e regras, que são essencialmente prescritivas e representativas das variedades de prestígio. Em outras palavras, a gramática normativa apresenta os usos tradicionalmente mais valorizados pela sociedade e é especialmente por esses motivos - tradição e valor social - que ainda continua a ser trabalhada na escola. O que se problematiza não é se se deve ensinar gramática normativa ou não, e sim a ênfase que se dá a esse tipo de gramática, em detrimento dos outros. Essa ênfase tem ofuscado o trabalho com outros tipos de gramática, a saber, a descritiva, a teórica e a reflexiva (cf. TRAVAGLIA, 2009; 2011), que podem, sem sombra de dúvidas, contribuir muito mais para o desenvolvimento da leitura e da escrita.

Segundo Travaglia (2011), a gramática reflexiva refere-se ao processo de levantamento das unidades, regras e princípios que constituem a língua em funcionamento, por meio de uma tentativa de entender a gramática implícita do falante. As atividades de gramática reflexiva levam o aluno a pensar, raciocinar, por meio da observação e reflexão sobre os recursos linguísticos. Ainda segundo o autor, a gramática teórica, por sua vez, engloba não só os estudos linguísticos que, com base numa atividade metalinguística, explicita a estrutura, a constituição e o funcionamento da língua, mas também envolve a parte descritiva das gramáticas normativas. $\mathrm{O}$ autor também defende que a justificativa para o ensino de gramática teórica encontra-se principalmente na necessidade de apresentar-se alguma metalinguagem que facilite a referência a certos recursos linguísticos, no desenvolvimento dos outros tipos de gramática. Já a gramática descritiva diz respeito à descrição das unidades e categorias linguísticas de determinada variedade da língua, sincronicamente, a partir da observação e levantamento de hipóteses pelo linguista.

Pretendemos, com a adoção dessas definições de gramáticas, defender aqui que o ensino de gramática deve ir além de normas prescritivas e voltar-se a um olhar mais descritivo e reflexivo, uma vez que acreditamos ser o mais apropriado ao desenvolvimento no aluno das competências leitora e escritora e, por isso, deveria ser o foco de atenção no ensino dos componentes gramaticais. 


\subsection{Descrição discursivo-funcional da oração subordinada adjetiva}

A fim de podermos entender melhor o funcionamento da oração adjetiva, faz-se necessário compreendermos suas diversas funções na construção do texto. No caso de nosso artigo, o objeto de estudo é o modo como a oração subordinada adjetiva é apresentada nos livros didáticos. Para melhor podermos fazer essa análise, precisamos nos filiar a uma teoria que estuda a gramática dentro de uma perspectiva discursivo-funcional, que vê a língua como um instrumento de interação verbal entre os seres humanos, isto é, como uma atividade humana estruturada e cooperativa (DIK, 1989). Assim, faremos uma breve exposição da função da oração adjetiva de acordo com a GDF, para, depois, contrastarmos o que será aqui exposto com o que encontramos nos LD.

Como já mencionado, adotamos a teoria da GDF (cf. HENGEVELD; MACKENZIE, 2008), que é uma teoria funcionalista organizada de modo hierárquico e descendente em quatro níveis: interpessoal, representacional, morfossintático e fonológico. Estabelece-se uma relação de prioridade entre os níveis na seguinte direção: o nível pragmático governa o semântico, ambos governam o morfossintático, e os três governam o fonológico.

No nível interpessoal, encontram-se as unidades linguísticas que desempenham algum papel interacional. A escolha dessas unidades reflete o jogo de pressuposições entre as informações pragmáticas dos interlocutores. A unidade de análise, que contém todo o conteúdo comunicado proferido pelo falante, denomina-se ato discursivo. A principal diferença entre a adjetiva explicativa e a adjetiva restritiva é que, diferentemente do proposto pela tradição gramatical, a adjetiva explicativa define-se pragmaticamente, e não semanticamente como a adjetiva restritiva. Mais especificamente, defende-se que a adjetiva explicativa é formulada como um ato discursivo. O status de ato da adjetiva explicativa comprova-se pelo fato de ser pronunciada com status ilocucionário e contorno entoacional independentes da oração principal. Vejamos os exemplos que seguem.

(1) Grazzi-Massafera, que é ex-participante de um reality show, concedeu entrevista a um site de revista. (FARACO et al., 2012, p. 76) 
(1') Grazzi-Massafera, que é ex-participante de um reality show, concedeu entrevista a um site de revista?

Em (1'), observa-se que a ilocução interrogativa atinge apenas a oração principal, enquanto a oração adjetiva contém ilocução declarativa, o que comprova que são dois atos com diferentes ilocuções. Além disso, ao se pronunciar a sentença, a adjetiva explicativa é pronunciada com tessitura mais baixa e velocidade mais rápida que o contexto linguístico em que se insere (cf. CÂMARA, inédito), ou seja, é pronunciada com um contorno entoacional independente do contorno do ato nuclear (oração principal), o que também comprova que se trata de atos distintos.

Os atos discursivos podem receber funções retóricas, definidas como propriedades formais que influenciam o ouvinte a aceitar os propósitos comunicativos do falante (cf. HENGEVELD; MACKENZIE, 2008, p.46). À adjetiva explicativa atribui-se a função retórica de aposição, responsável por atribuir informação de fundo sobre o núcleo nominal. Em (1), por exemplo, acrescenta-se a qualidade de ser ex-participante de um reality show a Grazzi Massafera. A informação trazida pela adjetiva explicativa é apenas adicional com relação às outras informações da sentença, entretanto contém uma função argumentativa fundamental. É justamente o fato de ela ser ex-participante de um reality show, e consequentemente ser uma personagem de destaque no meio televisivo, que lhe dá credibilidade para proferir uma entrevista.

O nível interpessoal também é responsável por atribuir certas funções pragmáticas ao conteúdo comunicado ou ao(s) subato(s) dentro do conteúdo. Dentre tais funções, destaca-se a função de tópico, que tem a função de assinalar como o conteúdo comunicado se relaciona ao registro construído gradualmente no contexto situacional e discursivo (HENGEVELD et al., 2008 , p. 92). O falante do enunciado em (1), ao atribuir a função pragmática de tópico ao subato Grazzi Massafera, assinala ao ouvinte que está partindo dessa informação tópica, já compartilhada por eles, para fazer a sua afirmação, ou seja, o tópico é a perspectiva a partir da qual o falante elabora sua mensagem. Ao pressupor que o ouvinte já sabe quem é Grazzi Massafera, o falante escolhe partir dessa informação para acrescentar a informação concedeu uma entrevista a um site de revista. As informações já dadas estão disponíveis no contexto e são ativadas como subatos com função de tópico na interação. $\mathrm{O}$ papel interacional dos tópicos, portanto, é promover a progressão temática do texto e contribuir para a coesão textual. 
Na GDF, o contexto tem um caráter mutável (cf. CONNOLY, 2007, p. 13): conforme o discurso prossegue, o contexto também muda, e vice-versa, pois cada sentença vai ser produzida/interpretada no contexto do que já foi dito até aquele momento e será acrescentada ao contexto em que serão produzidas novas sentenças. As sentenças já presentes no contexto são informações dadas, aquelas que entram no contexto são informações novas. Esse processo de acréscimo de informações ao contexto é visto de maneira metafórica, na GDF, como uma pilha em que as informações novas são inseridas no topo, levando as outras informações para baixo uma posição na pilha e, consequentemente, levam as últimas informações da pilha ao esquecimento.

Esse preenchimento dinâmico do componente contextual faz com que, devido às limitações de nossa memória, algumas informações desapareçam ao longo do discurso, enquanto outras se tornem mais proeminentes. Observe-se como o discurso responde ao empilhamento de indivíduos dentro do Estrato Representacional do componente contextual no poema de Ulisses Tavares extraído de uma atividade do livro Português Linguagens (2012, p. 39):

\section{(2) Natural retorno}

Opassarinho que a poluição

Espantou sou eu que voa

Para seus braços.

A água que a indústria sujou

Son en que desemboca limpido

Em sua barriga.

$[\ldots]$

O primeiro indivíduo (passarinho) inserido no texto é retomado pelo pronome relativo. A seguir, insere-se outro indivíduo (polvição) e, por fim, um terceiro indivíduo (eu), que também é retomado por um pronome relativo. Cada vez que um novo indivíduo é inserido no topo da pilha no componente contextual, os indivíduos anteriores caem uma posição, até desaparecerem completamente. Ao inserirem-se os próximos indivíduos (água e indústria), por exemplo, os dois primeiros indivíduos do poema provavelmente já não estão presentes na mente do ouvinte. Diferentemente de outros elementos de coesão, o pronome relativo é usado para fazer com que se mantenha, nesse processo de empilhamento de entidades, o mesmo indivíduo referido antes. 
Isso quer dizer que o pronome relativo é uma estratégia coesiva que retoma o indivíduo estocado por último no componente contextual e mantém, dessa forma, a mesma disposição de indivíduos.

O nível representacional, por sua vez, é responsável pelos aspectos semânticos das unidades linguísticas, independentemente da maneira como são usadas na comunicação. O termo "semântico" refere-se ao modo como uma língua se relaciona com os mundos possíveis que ela descreve. A oração subordinada adjetiva restritiva define-se semanticamente, nesse nível, como um modificador de núcleo nominal.

(3) Ao usar estes nomes, seremos mais fiéis à história dos povos que já estavam aqui antes mesmo de esta terra ser chamada Brasil. (TRAVAGLIA; ROCHA; ARRUDA-FERNANDES, 2012, p. 117).

A oração adjetiva restritiva, em (3), especifica o núcleo nominal povos, contribuindo para que o leitor faça a escolha adequada do referente, ou seja, dentre vários povos possíveis, o leitor deve escolher aquele que estava no território brasileiro antes da chegada dos portugueses. A informação veiculada pela adjetiva restritiva leva o leitor a formular uma imagem adequada do referente e a identificá-lo dentre um conjunto infinito de referentes possíveis (cf. DIK, 1997).

O nível morfossintático recebe o input dos níveis interpessoal e representacional e representa-os estruturalmente. Não há distinção estrutural entre os dois tipos de adjetivas, já que, em ambos os casos, um sintagma nominal recruta uma oração para formar uma estrutura mais complexa.

Por sua vez, o nível fonológico, no processo de conversão das estruturas morfossintáticas em construtos fonológicos, codifica cada tipo de oração adjetiva de modo específico. Diferentemente da adjetiva restritiva, a adjetiva explicativa é demarcada prosodicamente com relação à oração principal por apresentar um contorno entoacional próprio que a delimita como um sintagma entoacional (CÂMARA, inédito), como explicado anteriormente.

A descrição discursivo-funcional aponta para algumas características da oração subordinada adjetiva que podem ser relevantes para o ensino: (i) tanto a adjetiva restritiva quanto a explicativa funcionam como modificadores (constituintes opcionais, não obrigatórios); (ii) o pronome relativo desempenha uma importante função coesiva de retomada de informações já disponíveis contextualmente; (iii) a diferença entre adjetiva 
restritiva e explicativa não se limita ao âmbito semântico, devendo abranger também aspectos pragmáticos. Acreditamos que o aluno compreender essas características será importante para seu papel como leitor e autor de textos.

\section{Metodologia}

A escolha de LD para a compreensão do ensino da oração adjetiva na escola deve-se ao fato de serem, senão as únicas, as principais fontes de estudo e atualização para muitos docentes e de serem geralmente os materiais mais utilizados na sala de aula para o ensino do português. Estudos têm sido feitos sobre a relevância para o professor da utilização do livro didático em sala de aula, seja por ser um saber validado, seja por motivos de economia de tempo para preparar aula, seja para auxiliar o aluno em seus estudos etc. (CORACINI, 2011). Desde a implantação do Programa Nacional do Livro Didático (PNLD) em 19 de agosto de 1985 pelo Ministério da Educação (MEC) por meio do Decreto-Lei $n^{\circ}$ 91.542, o livro didático passou a ser um artefato de ensino legitimado pelo governo e prescrito pelo próprio momento histórico-social atual. Assim, o fato é que, só neste ano de 2014, 103.229.007 livros foram distribuídos para os alunos de Ensino Fundamental, conforme dados do site do Fundo Nacional de Desenvolvimento da Educação ${ }^{2}$. Partindo desse quadro, que revela a importância e a presença do LD na sala de aula, selecionamos os livros de língua portuguesa aprovados no PNLD-2014 para a análise a que nos propomos aqui.

\subsection{Seleção dos dados}

A seguir, apresenta-se a lista das coleções aprovadas no referido PNLD-2014 e analisadas neste artigo:

Jornadas.port-Lingua Portuguesa (DELMANTO; MATOS; CARVALHO, 2012)

Tecendo Linguagens (OLIVEIRA et al.; 2012)

Para viver juntos: português (MARCHETTI, G. et al.; 2012)

Coleção Perspectiva: Língua Portuguesa (DISCINO; TEIXEIRA; 2012)

${ }^{2}$ Informações extraídas do site <http://goo.gl/S6BLn2>. Acesso em: 10 abr. 2014. 
Português nos dias de hoje (FARACO; MOURA, 2012)

Português Linguagens (MAGALHÃES; CEREJA, 2012)

Português: uma língua brasileira (HORTA; MENNA; PROENÇA, 2012)

A aventura da linguagem (TRAVAGLIA; FERNANDES; ROCHA, 2012)

Singular \& Plural (FIGUEIREDO; BALTHASAR; GOULART, 2012)

Vontade de saber português (BRIGNEROT'TO; ALVES, 2012)

Universos (RAMOS; TAKEUKI, 2012)

Projeto Teláris (BORGATTO; BERTIN; MARCHEZI, 2012)

Após a seleção dos dados, que teve como critério a aprovação no PNLD-2014, procedeu-se à leitura atenta do manual dos professores de cada coleção a fim de verificarmos qual era a proposta de ensino apresentada nos manuais.

\subsection{A proposta de ensino de gramática presente nos manuais}

Cada LD traz anexada uma parte final, destinada à leitura do professor e denominada aqui Manual do Professor (doravante MP), em que se explicitam os pressupostos teóricos subjacentes à elaboração do material didático. No tocante ao tratamento dado à gramática, pode-se afirmar que a contextualização dos aspectos linguísticos é um dos pressupostos mais importantes. $\mathrm{Na}$ tentativa de ir além da abordagem tradicional do ensino de gramática, os MP, com base nas atuais teorias didático-pedagógicas, propõem um ensino diferenciado que focalize essencialmente o funcionamento dos aspectos gramaticais no texto. Propõe-se que o texto seja visto como unidade básica de ensino, ao qual as atividades de reflexão gramatical devem se subordinar. Às vezes, afirma-se inclusive que esse trabalho deve se voltar à explicitação de características dos gêneros textuais.

Neste sentido, é unânime nos MP a concepção de que o ensino de gramática deve voltar-se para a apropriação de recursos linguísticos, que devem ser usados na produção e compreensão de textos orais e escritos. Dessa forma, indo na contramão de um ensino transmissivo, defende-se um enfoque indutivo, em que primeiro há a construção do conceito pelo aluno por meio da observação do fenômeno, para posterior sistematização. Em outros termos, o ensino de gramática deve-se dar por meio de atividades de reflexão sobre o uso da língua, para, a seguir, chegar-se à teoria, diferentemente do caminho tradicional, que parte da apresentação da teoria e de exemplos para se chegar à prática. 
Partindo dessa concepção predominante, elaboramos algumas perguntas de pesquisa, que nos ajudaram na análise das atividades gramaticais referentes à oração adjetiva. São elas:

a) Qual a relação entre as atividades gramaticais e os textos (apresentados ou não nas unidades)?

b) A oração adjetiva é apresentada visando o processo de leitura e escrita tal como proposto nos MP? Se sim, como?

c) Qual o método mais frequente de apresentação da oração adjetiva nos LD?

\section{Resultados das Análises dos LD}

Para respondermos às perguntas de pesquisa apresentadas no item anterior, foram analisadas todas as seções de cada LD referentes à oração adjetiva e ao pronome relativo. Também se verificaram aquelas que falam sobre a coesão textual, já que, às vezes, também trazem algumas questões relacionadas ao tema. A seguir, promoveu-se a descrição de cada LD com base nas três perguntas relacionadas acima. Com isso, pretendíamos determinar as estratégias utilizadas pelos LD para fazer o aluno desenvolver as habilidades leitora e escritora por meio do estudo da oração subordinada adjetiva. Feitas essas análises, contrapomos a proposta de ensino de gramática presente nos MP, como descrita acima, com o que se apresenta nos LD sobre oração subordinada adjetiva para o aluno.

Inicialmente este trabalho pretendia analisar separadamente a apresentação do conteúdo e as atividades; entretanto, como há no LD uma dinâmica de intercalação entre conteúdo e exercícios, optou-se por descrever como se dá essa relação e, por isso, apresenta-se a análise da apresentação do conteúdo concomitantemente com a análise das atividades, tentando entender-se a relação existente entre elas.

Primeiramente, a análise nos revelou que a oração subordinada adjetiva é tratada normalmente no $9^{\circ}$ ano, seguindo a divisão gramatical clássica, em que primeiro se apresentam as classes de palavras, para, posteriormente, apresentarem-se os aspectos sintáticos da oração simples e, por fim, o período composto. Essa estruturação reflete a posição de análise linguística que parte de elementos menores (palavras) para elementos maiores (orações) e espelha uma visão de língua como um construto que vai de elementos linguísticos menores para elementos maiores. Tal perspectiva difere, em essência, daquela 
apontada nos MP, em que se defende a necessidade de partir do texto (unidade maior) para a análise dos aspectos gramaticais (unidade menor).

Salvo duas coleções, a maioria das coleções apresenta uma organização da obra em que as unidades seguem, aproximadamente, um mesmo padrão de divisão das seções, que vai da leitura para a produção de texto e, por último, para a reflexão sobre a língua. Tal percurso, ao mesmo tempo em que demonstra a subordinação dos aspectos gramaticais aos textuais, também significa uma divisão do trabalho com o português na tríade leitura - produção - gramática, o que contraria já de antemão a proposta dos MP. O livro Singular \& Plural (FIGUEIREDO; BALTHASAR; GOULART, 2012) propõe inclusive a divisão do conteúdo em cadernos autônomos: Caderno de leitura e produção, Caderno de práticas de literatura e Caderno de estudos de língua e linguagem, de modo similar à divisão realizada normalmente no Ensino Médio.

Duas palavras/ideias aparecem frequentemente no título das seções destinadas ao conteúdo gramatical: estudo e reflexão da língua. Enquanto a primeira se mostra mais neutra com relação à posição teórica adotada pelo livro, a segunda se justifica pela posição adotada nos MP, em que se declara a opção por tratar a gramática de modo reflexivo, levando o aluno a compreender os mecanismos linguísticos em seu funcionamento na arquitetura textual.

De modo geral, pode-se afirmar que há uma grande preocupação nos LD em se apresentar a gramática no texto. Mesmo assim, em alguns momentos, opta-se por fornecer aos alunos exemplos inventados e descontextualizados, principalmente nos momentos de conceitualização/ formalização da oração adjetiva. Alguns gêneros textuais são especialmente escolhidos nos LD nas seções de gramática, tais como histórias em quadrinhos, poemas, anúncios, reportagens. Além desses gêneros mais frequentes, são também usadas frases extraídas da internet. Também é muito comum estudar a oração subordinada adjetiva a partir de frases retiradas dos textos analisados na seção destinada à leitura e à escrita. É importante destacar aqui dois pontos. Em primeiro lugar, mesmo que a oração tomada como foco para a análise gramatical esteja situada em um texto real, independentemente de este texto estar ou não reproduzido na obra, normalmente não há nenhuma reflexão entre o uso da oração adjetiva e a produção dos sentidos dentro do texto. Isso quer dizer que, quando se extraem as frases de um texto, sem se realizar a volta ao texto durante a reflexão linguística, continua-se a ensinar gramática descontextualizada. Outro ponto a destacar é que há, nas seções de gramática, 
várias atividades de interpretação e compreensão de texto que quase nunca se relacionam ao uso da oração adjetiva. Tais atividades servem unicamente para discutir questões de entendimento do texto.

O percurso seguido prototipicamente pelos LD para a apresentação da oração adjetiva e dos pronomes relativos é: breve reflexão à conceito à atividades. Entende-se por 'breve reflexão' aqui algumas perguntas sobre a estrutura morfossintática da frase, que exigem que os alunos mobilizem conhecimentos gramaticais já apresentados em outros momentos, tais como o conceito de oração, de adjetivo, de adjunto adnominal etc. Esses conceitos são utilizados para fazer o aluno refletir sobre a estrutura morfossintática da oração subordinada adjetiva, e raramente se faz uma reflexão sobre a função da oração adjetiva na produção dos sentidos do texto.

A apresentação da oração adjetiva, portanto, inicia-se com uma breve reflexão que consiste ou na substituição da oração adjetiva por um adjetivo, ou na identificação das orações que caracterizam o substantivo. Juntamente com essa breve reflexão, mobilizada por meio de uma pergunta, há frequentemente atividades sobre identificação e classificação da oração subordinada, da oração principal e dos antecedentes. As atividades a seguir, por exemplo, iniciam o trabalho com a oração adjetiva no livro Tecendo Linguagens (OLIVEIRA et al., 2012, p. 199):

(4) Releia o trecho a seguir com atenção.

"A escolha da profissão deve ser o resultado de um processo que envolve a investigação e ponderação de interesses, habilidades e valores do futuro profissional, as oportunidades dos sistemas de educação e as possibilidades do mundo do trabalho."

a) A oração destacada relaciona-se com a oração anterior por meio do conectivo que, um pronome relativo. Esse conectivo substitui um termo já expresso anteriormente. Qual seria ele?

b) Qual é a função sintática do pronome relativo nesse contexto?

(5) Releia agora apenas este trecho: "A escolha da profissão deve ser o resultado de um processo que envolve a investigação [...]".

a) Reescreva o trecho acima, substituindo a oração destacada por uma única palavra.

b) A que classe gramatical pertence essa palavra? 
Em (4), a partir de um trecho extraído de um texto discutido na seção de leitura, o livro pede que se identifique o antecedente e a função sintática do pronome relativo. Também se propõe, em (5), que os alunos substituam a oração adjetiva por um adjetivo para perceberem a equivalência entre eles.

Após essa breve reflexão, os LD partem para a apresentação e exemplificação do conceito, normalmente em seções específicas ou em boxes destacados por cores diferentes. As orações subordinadas adjetivas são definidas nos LD como (i) subordinadas porque dependem sintaticamente da oração principal; (ii) adjetivas porque exercem função de um adjetivo; (ii) tendo a função de caracterizar, descrever, especificar, esclarecer, detalhar, determinar o antecedente; e (iv) sendo introduzidas por pronome relativo. A distinção entre os dois tipos de adjetivas se estabelece de duas formas. Alguns livros as diferem pela possibilidade de omissão da oração explicativa, que deve vir destacada da oração principal por vírgulas. O aluno é levado a perceber que, ao omitir-se a adjetiva explicativa, o período ainda fica com sentido completo, não tem a estrutura sintática prejudicada e não tem a compreensão comprometida. Outros livros tentam levar o aluno à reflexão sobre a diferença de sentido entre restritivas e explicativas. Enquanto a restritiva particulariza o termo, a explicativa acrescenta uma informação adicional. Segundo os LD, a oração adjetiva restritiva (i) é essencial ao sentido e à estrutura do enunciado, (ii) não é separada por vírgulas, (iii) restringe, delimita, especifica o sentido de um termo. A oração adjetiva explicativa (i) explica um termo antecedente, apresentando-lhe informação adicional; (ii) não é essencial ao sentido do enunciado; (iii) vem entre vírgulas; (iv) assemelha-se ao aposto; (v) acrescenta informação já conhecida pelo interlocutor.

De maneira geral, os LD tentam apresentar a oração subordinada adjetiva a partir de um ensino indutivo, que parte da reflexão sobre os fatos para posterior elaboração do conceito, assim como proposto pela maioria deles nos MP. No entanto, verifica-se que normalmente essa reflexão é feita muito rapidamente e apenas sobre um aspecto da oração adjetiva, enquanto a apresentação do conceito é detalhadamente elaborada. Desse modo, pode-se afirmar que os LD analisados tentam mudar a postura tradicional de ensinar gramática, porém priorizam um ensino que parte essencialmente da apresentação teórica para as atividades.

Após a apresentação do conceito, apresenta-se uma série de atividades, que consistem basicamente na exercitação de nomenclatura e na identificação e classificação da oração adjetiva e de seus subtipos. Entretanto há algumas 
atividades que se destacam ou por mobilizarem os sentidos promovidos pelo uso das orações adjetivas restritivas e explicativas, ou por exigirem a criação de frases e textos em que haja orações adjetivas.

De fato, o trabalho com os sentidos advindos do uso da oração adjetiva é uma preocupação da maioria dos LD. Normalmente, propõem-se atividades em que os alunos consigam distinguir os subtipos de adjetivas a partir da diferença de sentido veiculado por elas. Enquanto a restritiva restringe, particulariza, especifica o núcleo, sendo parafraseada por apenas, a explicativa explica o núcleo, sendo parafraseada por todo e qualquer. No livro Tecendo Linguagens (OLIVEIRA et al., p. 199), por exemplo, pede-se que se identifique o sentido (explicar, acrescentar informação ou restringir) da oração adjetiva na frase Muitos profissionais, que se sentem cansados, optam por realizar outros tipos de trabalho.

Raras atividades levam o aluno a compreender o funcionamento das orações adjetivas no texto, como a atividade a seguir do livro Português Linguagens (MAGALHÃES; CEREJA, 2012, p.61-62):

(6) Considerando-se que a finalidade de uma tira é criar humor, qual é a importância das orações adjetivas na construção desse texto?
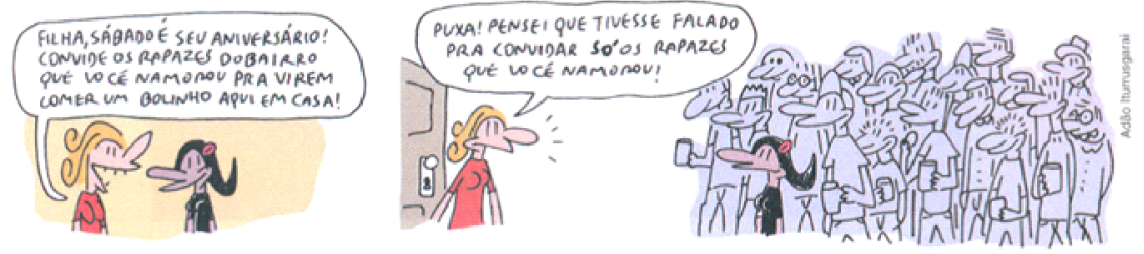

Nessa atividade, o aluno é levado a pensar sobre a diferença de usos entre os dois tipos de adjetivas, percebendo que o humor está justamente no fato de a adjetiva restritiva que você namorou ter a função de especificar, dentre o conjunto de meninos do bairro, apenas aqueles que a personagem namorou. Entretanto, quando a mãe vê uma grande quantidade de meninos do bairro em frente à sua casa, entende que a menina namorou todos. O humor encontra-se justamente na ironia presente na fala da mãe ao usar a partícula só no segundo quadrinho, o que reforça a função da oração adjetiva restritiva que havia sido formulada inicialmente, demonstrando o contraste existente entre as expectativas da mãe e a cena com que se depara. 
É comum também se relacionar a diferença de sentido entre as duas adjetivas à dispensabilidade da adjetiva explicativa, em comparação à obrigatoriedade da adjetiva restritiva. Seguindo o pressuposto de que a adjetiva explicativa pode ser omitida sem prejudicar o sentido e a gramaticalidade da frase, o aluno é levado a diferenciar as adjetivas restritivas e explicativas a partir desse critério. No entanto, ao analisar as frases dadas como exemplo nos LD, percebe-se que, apesar da omissão da adjetiva explicativa, a frase continua gramaticalmente aceitável e compreensível para o leitor.

O livro didático Universos (RAMOS; TAKEUKI, 2012, p. 261), por exemplo, leva os alunos a compreenderem a diferença de sentido entre restritiva e explicativa a partir da possibilidade de se omitir as adjetivas nas construções:

(7) $\mathrm{Na}$ apresentação, clássicos se misturam a faixas do recente 'Brasil Afora' (2009), álbum que originou a última turnê.

(8) O cantor, que completa este ano 47 anos de carreira, traz para o evento multilinguagem baladas românticas como 'Doce Doce Amor'.

Na primeira sentença, não é possível omitir que originou a última turnê, pois é justamente a oração adjetiva restritiva que especifica o núcleo álbum. Sem essa informação, o Ouvinte não constrói uma imagem mental do referente. A agramaticalidade de Na apresentação, clássicos se misturam a faixas do recente 'Brasil Afora' (2009), álbum, advinda da omissão da adjetiva, explica-se pelo fato de restar apenas um sintagma nominal (álbum), que informacionalmente não é suficiente para constituir o parêntese, e não pela natureza da adjetiva restritiva, que, por ser modificador, não é estruturalmente obrigatória.

A omissão da adjetiva explicativa em $O$ cantor, que completa este ano 47 anos de carreira, trazpara o evento multilinguagem baladas românticas como Doce Doce Amor', citada no mesmo texto, não prejudica a gramaticalidade da sentença, entretanto compromete o sentido (ou melhor, o poder argumentativo) do texto. Considere-se a construção textual: 
(9) Leia a notícia abaixo, tirada de um site de entretenimento.

\section{Sarau du Brown reune Stomp Experience \& Projeto Quabales e Paralamas do Sucesso}

Carlinhos Brown recebe no palco do Museu du Ritmo, neste domingo, os ingleses do Stomp Experience \& Projeto Quabales. Assim como nosso Cacique, os ingleses criam músicas com instrumentos não convencionais como vassouras, toneis, latas e o próprio corpo. No mesmo dia, divide também o palco com o artista baiano um dos grandes lideres da Velha Guarda, Jerry Adriani. O cantor, que completa este ano 47 anos de carreira, traz para o evento multilinguagem baladas românticas como 'Doce, Doce Amor".

E a noite segue no Sarau com o Rock in Roll dos Paralamas do Sucesso. Na apresentação, clássicos se misturam a faixas do recente "Brasil Afora" (2009), álbum que originou a última turnê. Quem também participa do evento é a cantora baiana Márcia Castro. Para os conterrâneos, ela apresenta o mais recente trabalho, a nova versão da música "Preta, Pretinha", de Moraes Moreira.

A adjetiva que completa este ano 47 anos de carreira traz uma informação que o escritor julga necessário acrescentar à informação pragmática do leitor, visando atingir determinados objetivos comunicativos. No texto em (9), o objetivo do escritor é construir uma imagem, para o referente cantor, de pessoa experiente no campo musical, conferindo-lhe o poder de fazer um excelente show. Essa imagem do referente é comprovada pelo uso do sintagma nosso cacique, que foi citado antes no texto para se referir ao cantor Carlinhos Brown e que também traz a ideia de pessoa experiente e sábia na área musical.

Tendo em vista o exposto, defende-se, portanto, que a possibilidade de omissão das adjetivas se relaciona com a quantidade de informação que veicula sobre o núcleo e a relevância dessa informação para a sua identificação ou caracterização, e não com uma característica intrínseca à adjetiva restritiva de não poder ser omitida. Além disso, a omissão da adjetiva restritiva e da adjetiva explicativa pode não prejudicar a gramaticalidade e, consequentemente, a compreensão da sentença, mas restringe a quantidade de informação semântica ou pragmática conferida ao núcleo.

Outra questão tratada nos LD sobre a oração adjetiva e que se relaciona com a coesão textual é a identificação do antecedente do pronome relativo. Normalmente, os LD apenas pedem que se identifique o núcleo sem levar a 
nenhuma reflexão sobre o papel coesivo dos pronomes relativos. Em algumas atividades, pede-se que o aluno una dois períodos simples em um período composto ou se pede que transforme um período composto por oração adjetiva em dois outros períodos simples, sem nenhuma reflexão sobre a diferença entre as duas estratégias, como na atividade abaixo do livro Jornadas.port (DELMANTO; CARVALHO, 2012, p.170).

(10) No caderno, reescreva cada item, transformando os dois períodos em um só. Empregue o pronome relativo adequado e exclua as palavras repetidas.

a) Os indígenas valorizam muito a terra. A terra lhes dá o sustento.

b) Os homens valorizavam a região. Os homens nasceram nessa região.

Esse tipo de atividade é uma ótima oportunidade para se mostrar o mecanismo coesivo dos pronomes, o que seria muito relevante para promover uma reflexão sobre a função dos pronomes no texto. É claro que isso só seria possível em frases contextualizadas, diferentemente das que aparecem normalmente nesse tipo de atividade. Uma iniciativa interessante, mas pouco desenvolvida pelos LD, é propor ao aluno a reescrita de um texto com palavra(s) repetida(s), usando pronomes relativos ou orações adjetivas para evitar essas repetições. Nesse caso, o aluno é levado a perceber para que servem os pronomes e como deve utilizá-los. Observe-se essa tentativa na atividade do livro Português Linguagens (CEREJA; MAGALHÃES, 2012, p.63):

(11) Reescreva o texto seguinte, tornando-o claro, coeso e enxuto. Para isso, elimine as repetições, empregando orações adjetivas, pronomes e outros elementos que achar adequados.

Eu conheci um garoto e uma garota. Eles são irmãos. O garoto e a garota mudaramse para minha classe. No começo, ninguém deu muita atenção para o garoto e a garota. O garoto e a garota são tímidos, magrelos e meio desajeitados. Hoje, na aula de computação, o garoto e a garota deram um show. Eles são feras no teclado! A turma ficou boquiaberta e en fiquei caído pela garota. Ai, meu Deus! Tomara que eu seja correspondido! 
Essa é uma interessante atividade sobre o uso dos pronomes relativos que leva o aluno a refletir sobre seu papel coesivo, entretanto a artificialidade do texto dificulta identificá-lo com um determinado gênero textual. Além disso,o texto assemelha-se a uma escrita diarista ou ao discurso oral informal, em que a repetição é condizente com a própria modalidade, comprometendo a justificativa e o objetivo da atividade. Seria mais interessante trabalhar com textos autênticos (se possível, de autoria do próprio aluno), fazendo-o refletir sobre a presença/ausência dos pronomes relativos e levando-o, consequentemente, a perceber que essa estratégia coesiva permite organizar as ideias com mais clareza.

O livro Universos (RAMOS; TAKEUKI, 2012, p.157-8) é o único que propõe uma atividade em que se relaciona a adjetiva com o gênero textual enciclopédico, como exemplificado a seguir.

(12) Releia os trechos a seguir.

I. "A Irmandade de Nossa Senhora da Boa Morte nasceu nas senzalas, locais que abrigavam escravos negros nos engenhos de cana-de-açúcar, há cerca de 150 anos."

II. "Mistura de herança africana com toques da cultura portuguesa, a Congada representa a coroação dos reis congos, que desfilam mascarados e trajados com fardas ornamentadas de ouro e diamantes, cercados do bailado dos guerreiros."

[...]

b) Qual é a função das orações destacadas em relação aos termos referidos? Copie a opção correta no caderno.

Opção 1 - Caracterizá-los, acrescentando juízos de valor ao que é dito.

Opção 2 - Caracterizá-los, transmitindo informações de forma mais objetiva. (CORRETA)

$[\ldots]$

d) Considere sua resposta à atividade 4b. Qual é a importância, num texto enciclopédico, da função identificada?

Essa atividade tenta promover, de forma inovadora, uma relação entre o sentido promovido pela adjetiva e o gênero enciclopédico, o que se deve ao fato de a adjetiva contribuir para a caracterização objetiva dos núcleos. Entretanto, também pode levar a uma equivalência equivocada entre a função 
da oração adjetiva e as características da enciclopédia. A função de caracterizar transmitindo informações de forma mais objetiva não é uma característica própria da oração adjetiva, mas do próprio gênero. A pergunta (4-b) poderia levar ao equívoco de se pensar que a adjetiva nunca acrescenta juízo de valor sobre o núcleo, o que não é verdade.

Por fim, verificou-se que alguns livros didáticos apresentam atividades em que os alunos devem produzir frases ou textos em que haja orações adjetivas. Apenas três LD pedem que se produzam textos usando orações adjetivas. O livro $A$ aventura da linguagem, por exemplo, pede que se escreva um texto usando adjetivos e orações adjetivas, como na atividade a seguir (TRAVAGLIA; FERNANDES; ROCHA, 2012, p. 345):

(13) Construa um pequeno texto, empregando pelo menos dois adjetivos e duas orações para caracterizar seres aos quais substantivos e pronomes se referem.

Nota-se que as atividades que tentam levar o aluno a aplicar o conteúdo gramatical à sua produção escrita ainda são pouco frequentes e quase sempre não há uma proposta de produção bem estruturada que leve o aluno a uma produção autêntica. Exercícios de completar frases dificilmente contribuem para o desenvolvimento de habilidades de escrita. E atividades de construção de texto em que não fica clara a situação de comunicação tampouco parecem muito eficientes para o desenvolvimento da capacidade de escrita. Como proposto por diversas teorias do ensino de gêneros e produção escrita, a mobilização dos elementos do contexto de produção (o papel social do autor naquela atividade de produção, o papel social de seu destinatário, o objetivo e efeito de sentido que quer causar no leitor, o momento da produção, o local da produção, o gênero mais apropriado para se atingir o objetivo pretendido, assim como o local de publicação) são informações sem as quais a atividade de escrita torna-se um mecanismo artificial e mecânico de ensino de língua.

Em síntese, a análise das atividades sobre a oração subordinada adjetiva demonstrou que predominam nos LD as atividades de gramática teórica, já que os LD exploram essencialmente a apropriação de metalinguagem e de nomenclatura referentes ao tema. No entanto, também há atividades do tipo gramática descritiva, como aquelas em que se pede para preencher lacunas 
com orações adjetivas e produzir texto com oração adjetiva. Entretanto, essas atividades normalmente apresentam exemplos descontextualizados e textos artificiais, além de serem exercícios mecânicos sobre a língua. O conhecimento das unidades e regras da língua deve vir associado à reflexão sobre o funcionamento dos aspectos linguísticos no texto, como em certas atividades de identificação da diferença de sentido entre restritiva e explicativa. Mas isso acontece com frequência bem inferior às atividades de nomenclatura e metalinguagem.

Enfim, a proposta de se ensinar gramática no texto é de fato uma preocupação dos LD, entretanto se percebe que isso raramente ocorre no tratamento dado à oração adjetiva. Este artigo propõe inverter-se o enfoque dado a esse tema nos LD. Acreditamos que seria mais relevante que o aluno entendesse quais os usos da oração subordinada adjetiva no texto em que se insere e, para atingir esse objetivo, deve-se ampliar o espaço dado às atividades de gramática reflexiva, para que o aluno perceba como as orações adjetivas são usadas para produzir diferentes efeitos de sentido. Somente após esse percurso, seria apresentado algum tipo de metalinguagem e de nomenclatura.

\section{Considerações Finais}

O ponto de vista adotado aqui é que o objetivo principal da escola não é ensinar teoria linguística, mas priorizar um ensino de gramática que possa contribuir de fato para o desenvolvimento das habilidades de leitura e escrita. Posicionamo-nos contrariamente a qualquer posição extremista, seja ela trabalhar exclusivamente com a gramática normativa ou abandoná-la completamente, já que estamos cientes do poder que a variedade padrão tem na sociedade atual, assim como o fato de o trabalho com a norma fazer parte de uma tradição escolar com a qual não estamos nos opondo. O que se propõe é que se trabalhe também e prioritariamente com uma gramática que leve à reflexão sobre os usos da língua e contribua para um melhor uso nas mais diversas situações comunicativas. Assim, espera-se que o aluno desenvolva sua criticidade no entendimento do funcionamento de sua língua materna.

Nas análises efetuadas, constatamos que a maioria dos MP afirma que o ensino de gramática deve subordinar-se ao texto, ou seja, deve servir à explicitação dos recursos linguísticos presentes em dado texto, visando o desenvolvimento da capacidade leitora e escritora. Entretanto, o que realmente se verifica é que apenas uma minoria estuda a gramática no seu funcionamento 
intratextual. Quase sempre, as frases são extraídas do texto e ganham vida própria, desconsiderando-se totalmente a sua relação com outras palavras e orações dentro do texto em que se inserem. Muito frequentemente, exige-se que o aluno volte ao texto para identificação do antecedente, mas normalmente isso é feito com pouca reflexão sobre o papel coesivo do pronome relativo.

É desnecessário dizer, portanto, que majoritariamente a oração subordinada adjetiva não é aprendida visando à leitura e à escrita. É ocioso dizer também que ensinar análise sintática e metalinguagem não auxilia em nada no desenvolvimento da leitura e da escrita. Ao contrário, para levar o aluno a ler e escrever melhor, dever-se-ia evidenciar quais as funções das orações adjetivas na construção do texto.

Partindo-se do fato de que o texto é uma atividade interativa, em que subjazem, além dos propósitos comunicativos do escritor, os fatores socioculturais e contextuais, propõe-se que a oração adjetiva seja primeiramente apresentada aos alunos em seu funcionamento na arquitetura textual. Apenas após uma reflexão bem detalhada sobre isso, o aluno deve ter contato com atividades de exercitação de metalinguagem e de nomenclatura, que, contrariamente à nossa proposta, são predominantes em quase todos os LD aqui analisados e, frequentemente, são o fim último do ensino da oração subordinada adjetiva.

Como a oração subordinada adjetiva se define por seu funcionamento no texto, e não intraoracionalmente, é indispensável que seu estudo abranja a organização discursivo-textual, explicitando os vários níveis constitutivos da gramática da língua. Neste sentido, foram discutidos alguns aspectos da descrição discursivo-funcional que são de extrema relevância para o ensino.

Em primeiro lugar, percebe-se que, ao se basear exclusivamente em critérios semânticos (restringir/explicar), os LD nem sempre descrevem adequadamente a diferença entre adjetivas restritivas e explicativas, já que, como se demonstrou, esses dois tipos se definem em diferentes níveis gramaticais, semântico e pragmático, respectivamente. E é por isso que se propõe aqui que a oração subordinada adjetiva seja ensinada a partir da reflexão sobre o seu funcionamento no texto, ou seja, deve-se levar o aluno a refletir sobre os efeitos de sentido que o uso de uma oração adjetiva explicativa ou restritiva pode causar no leitor/ouvinte.

Outra contribuição da GDF diz respeito à questão da possibilidade de se omitir a oração adjetiva. Normalmente, distinguem-se os dois tipos de oração adjetiva pelo fato de apenas a explicativa poder ser omitida. Entretanto, 
como se comprovou, as duas orações adjetivas podem ser omitidas sem prejudicar a gramaticalidade da sentença, pois são modificadores, e não constituintes obrigatórios, por isso diferenciá-las a partir da (im)possibilidade de omissão não é um critério válido. Apesar de as adjetivas não serem constituintes obrigatórios, sua omissão pode comprometer a construção dos sentidos veiculados pelo texto de diferentes maneiras, já que cada uma é usada com um propósito na interação. Enquanto a restritiva serve para a identificação de um referente pelo leitor, a explicativa tem poder argumentativo e acrescenta uma informação de fundo sobre o referente, contribuindo para que o escritor atinja seus objetivos comunicativos.

Mais um conceito importante para a compreensão da oração adjetiva é o de tópico (cf. seção 1.2). Defende-se aqui que o pronome relativo, ao referir-se anaforicamente a certas informações do contexto, é escolhido pelo falante como tópico da sentença. Ao usar uma oração adjetiva, o falante parte necessariamente de uma informação já presente no contexto situacional ou discursivo e, portanto, compartilhada pelos falantes no momento da interação. Esse papel coesivo anafórico já é notado nos LD em diversas atividades, como aquelas em que se pede para o aluno identificar o núcleo a que o pronome se refere ou unir períodos simples em compostos evitandose a repetição de termos. Entretanto, essas atividades normalmente não levam os alunos a refletirem sobre o uso coesivo dos pronomes na construção do texto, pois são atividades exclusivamente mecânicas. É importante que o aluno perceba o processo de construção textual, em que as entidades já inseridas no contexto ficam à disposição para serem retomadas ao longo do texto. Também é necessário que o aluno perceba que o pronome relativo é uma estratégia coesiva que serve para retomar uma informação imediatamente anterior, assim como outras estratégias, como sujeito "oculto", pronomes pessoais, nominalizações, etc..

Deve-se também notar que, diferentemente de outras estratégias coesivas, como as nominalizações, por exemplo, que trazem uma avaliação subjetiva do escritor, o pronome relativo não tem poder argumentativo, funcionando apenas como um elo coesivo. É indispensável, portanto, que se contraste o funcionamento dos pronomes relativos com outras estratégias coesivas, e isso só é possível considerando o funcionamento da oração adjetiva no texto.

Para finalizar, destacamos a produtividade de se realizar uma interface entre as propostas dos estudos linguísticos sobre aspectos descritivos da língua 
e o ensino de gramática na escola. Tal interface contribui para se repensar o modo como os tópicos gramaticais são ensinados. Apesar de o enfoque deste artigo ser restrito à oração subordinada adjetiva, demonstramos a importância de se relacionar o ensino de gramática à compreensão e produção de textos, visando o desenvolvimento nos alunos tanto da competência gramatical como da textual.

\section{Referências}

ANTUNES, I. Muito além da gramática: por um ensino de línguas sem pedras no caminho. São Paulo: Parábola, 2007.

BAGNO, M. Nada na língua é por acaso: por uma pedagogia da variação lingüística. São Paulo: Parábola Editorial, 2007.

BAGNO, M. Gramática pedagógica do português brasileiro. São Paulo: Parábola, 2011.

BRASIL. Ministério da Educação. Guia de Livros Didáticos PNLD 2014: língua portuguesa/ensino fundamental/anos finais. Brasília: Ministério da Educação, Secretaria de Educação Básica, 2013.

CÂMARA, A. L. A codificaşão fonológica da oração relativa. (inédito)

CASTILHO, A. T. Nova gramática do português brasileiro. São Paulo: Contexto, 2010.

CONNOLLY, J. H. Context in functional grammar. Alfa, São Paulo, v. 51, n. 2, p. 11-33, 2007.

CORACINI, M. J. R. F. O processo de legitimação do livro didático na escola de ensino fundamental e médio: uma questão de ética. In:

CORACINI, M. J. R. F. (Org.) Interpretação, autoria e legitimação do livro didático. 2. ed. Campinas: Pontes, 2011. p. 33-43.

DIK, S. C. The theory of Functional Grammar. Part I: The structure of the clause. Dordrecht: Foris, 1989.

DIK, S. C. The theory of Functional Grammar. Part 1: The structure of the clause. Berlin; New York: Mouton de Gruyter, 1997. (ed. Kees Hengeveld) 
FRANCHI, C. Criatividade e gramática. Trabalhos em Lingüistica Aplicada, Campinas, n. 9, p. 5-45, 1987. Disponível em: <http://goo.gl/JRwUEV>. Acesso em: 3 abr. 2014.

HENGEVELD, K.; MACKENZIE, J. L. Functional discourse grammar: a typologically-based theory of language structure. Oxford: Oxford University Press, 2008.

NEVES, M. H. M. Reflexões sobre o estudo da gramática nas escolas de $1^{\circ}$ e $2^{\circ}$ graus. Alfa, São Paulo, v. 91, n. 37, p. 91-98, 1993.

NEVES, M. H. M. A gramática: história, teoria e análise, ensino. São Paulo: Editora Unesp, 2002.

NEVES, M. H. M. Que gramática estudar na escola? 4. ed. São Paulo: Contexto, 2011.

POSSENTI, S. Por que (não) ensinar gramática na escola. Campinas:

Mercado de Letras, 1996.

TRAVAGLIA, L. C. Gramática e interação: uma proposta para o ensino de gramática. 14. ed. São Paulo: Cortez, 2009.

TRAVAGLIA, L. C. Gramática ensino plural. 5. ed. São Paulo: Cortez, 2011.

\section{Obras analisadas}

BRUGNEROTTO, T.; ALVES, R. Vontade de saber português. São Paulo: FTD, 2012.

DELMANTO, D. A.; MATOS, F.; CARVALHO, L. B. Jornadas.port Língua Portuguesa. 2. ed. São Paulo: Saraiva, 2012.

DISCINO, N.; TEIXEIRA, L. Coleção Perspectiva: Língua Portuguesa. 2. ed. São Paulo: Editora do Brasil, 2012.

FARACO, C. E.; MOURA, F. M. Português nos dias de hoje. São Paulo: Leya, 2012.

FIGUEIREDO, L.; BALTHASAR, M.; GOULART, S. Singular \& Plural Leitura, produção e estudos da linguagem. São Paulo: Moderna, 2012. 
HORTA, R. F.; MENNA, L.; PROENÇA, G. Português: uma língua brasileira. São Paulo: Leya, 2012.

MAGAlHÃES, T. A. C.; CEREJA, W. R. Português Linguagens. 7. ed. São Paulo: Saraiva, 2012.

MARCHETTI, G. et al. Para viver juntos: português. 3. ed. São Paulo: Edições SM, 2012.

MARCHEZI, V. L. de C.; BERTIN, T. C. H.; BORGATTO, A. M. T. Projeto Télaris - Português. São Paulo: Ática, 2012.

OLIVEIRA, T. A. et al. Tecendo Linguagens. 3. ed. São Paulo: IBEP, 2012. RAMOS, R. de A.; TAKEUKI, M. Universos Lingua Portuguesa. São Paulo: Edições SM, 2012.

TRAVAGLIA, L. C.; FERNANDES, V. M. B. A.; ROCHA, M.A. de F. A aventura da linguagem. 2. ed. Belo Horizonte: Dimensão, 2012.

Recebido em: 27/05/2014 Aceito: $19 / 09 / 2014$ 